\title{
Jolkinolide B induces apoptosis in MDA-MB-231 cells through inhibition of the PI3K/Akt signaling pathway
}

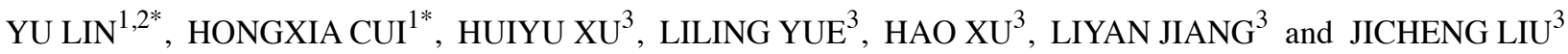 \\ ${ }^{1}$ Department of Pharmacology, Qiqihar Medical University, Qiqihar 161006; ${ }^{2}$ Heilongjiang University of Chinese \\ Medicine, Harbin 150040; ${ }^{3}$ The Institute of Medicine, Qiqihar Medical Univeristy, Qiqihar 161006, P.R. China
}

Received December 2, 2011; Accepted February 21, 2012

DOI: $10.3892 /$ or.2012.1717

\begin{abstract}
The phosphoinositol-3-kinase (PI3K)/Akt signal transduction pathway is critically important for tumor cell growth, proliferation and apoptosis. Apoptosis activation has been reported to be a good target in cancer therapies. In this study, we have found that jolkinolide B (JB), a diterpenoid from the traditional Chinese medicinal herb Euphorbia fischeriana Steud, strongly inhibited the expression of the PI3K p85 subunit and the phosphorylation of Akt. Furthermore, we evaluated the effects of $\mathrm{JB}$ on the proliferation and apoptosis of MDA-MB-231 human breast cancer cells. Our results show significant induction of apoptosis in MDA-MB-231 cells incubated with JB. This effect was enhanced by combination with LY294002. In addition, treatment with JB could induce downregulation of the $\mathrm{Bcl}-2 / \mathrm{Bax}$ ratio, and subsequent promotion of mitochondrial release of cytochrome $\mathrm{c}$ and activation of caspase-3. Taken together, JB-induced apoptosis of MDA-MB231 cells occurs through the mitochondrial pathway. Further, the PI3K/Akt signaling cascade plays a role in the induction of apoptosis in JB-treated cells. These observations suggest that JB may have therapeutic applications in the treatment of cancer.
\end{abstract}

\section{Introduction}

Apoptosis (programmed cell death) has become one of the popular research areas in cancer therapy. It has been shown that inducing tumor cell apoptosis is one of the important mechanism of many chemotherapeutic agents $(1,2)$. The execution of apoptosis is associated with biochemical changes mediated by various genes and cell signaling pathways, such as the phosphoinositide 3-kinase (PI3K)/Akt survival pathway.

Correspondence to: Dr Jicheng Liu, The Institute of Medicine, Qiqihar Medical Univeristy, 333 BuKui Street, JianHua District, Qiqihar 161006, P.R. China

E-mail: qyybliu@sohu.com

${ }^{*}$ Contributed equally

Key words: jolkinolide B, apoptosis, MDA-MB-231 cells, PI3K/Akt
The PI3K/Akt signaling is a significant transduction pathway which plays a key regulatory function in cell proliferation, apoptosis and the cell cycle $(3,4)$. Class IA PI3K, the type most widely implicated in cancer, is a heterodimeric lipid kinase consisting of a p85 regulatory subunit and a p110 catalytic subunit (5). This pathway is activated by survival signals such as cytokines, growth factors and hormones (6).Activation of PI3K results in the phosphorylation of Akt. Mutation of this pathway has been found in about $70 \%$ of breast cancer patients (7). There is an excessive expression and activation of Akt in various malignant tumors, such as gastric and prostate cancer $(8,9)$.

Jolkinolide B (JB), a diterpenoid component, isolated from the dried roots of Euphorbia fischeriana Steud, has shown significant antitumor activities against Sarcoma 180 and Ehrlich ascites carcinoma in mice (10). It has been reported that $\mathrm{JB}$ regulates proliferation and induces apoptosis in human prostate LNCaP cancer and K562 cells in vitro $(11,12)$. In the present study, we aimed to investigate the effects of JB on cell proliferation and the induction of apoptosis in MDA-MB-231 breast cancer cells and to examine whether its effects are associated with the PI3K/Akt signaling pathway.

\section{Materials and methods}

Materials. JB (molecular weight of 330.4, purity >99\%) (structure, Fig. 1) was kindly provided by Professor Shujun Zhang (Chemical Engineering Institute, Qiqihar University). JB was dissolved in dimethylsulfoxide (DMSO) to make a stock solution at a concentration of $100 \mathrm{mM}$, which was further diluted to the appropriate concentration with culture medium before each experiment. Control experiments contained DMSO.

Cell line and cell culture. The human breast cancer cell line MDA-MB-231 was purchased from the Cell Bank of the Type Culture Collection of the Chinese Academy of Sciences (Shanghai, China). Cells were maintained in L15 medium (Gibco, Invitrogen Corp., USA) supplemented with $10 \%$ fetal bovine serum at $37^{\circ} \mathrm{C}$ with $5 \% \mathrm{CO}_{2}$ and digested with $0.25 \%$ trypsin.

Cell viability assay. To measure cell viability, cells were seeded into 96 -well plates $\left(5 \times 10^{3}\right.$ cells/well) and incubated overnight. Subsequently, they were incubated with different 


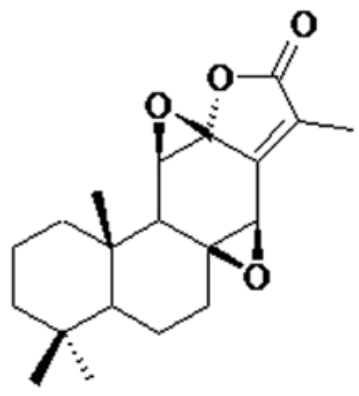

Figure 1. Chemical structure of jolkinolide B.

concentrations of JB for 12, 24 or $48 \mathrm{~h}$. After treatment, $20 \mu \mathrm{l}$ of MTT [3-(4,5- dimethylthiazol-2-yl)-2,5-diphenyltetrazolium bromide] solution (final concentration, $500 \mu \mathrm{g} / \mathrm{ml}$ ) was added in each well and incubated continuously at $37^{\circ} \mathrm{C}$ for $4 \mathrm{~h}$. Next, the medium was removed from all the wells and mixed with $150 \mu \mathrm{l}$ of DMSO. The absorbance for each well was measured at the wavelength of $570 \mathrm{~nm}$ by a microplate reader (Safire2, Tecan Group Ltd., Maennedorf, Switzerland). Cell viability was determined as a percentage of viable cells in JB-treated vs. untreated controls. The MTT assay was performed at each time point for three independent experiments.

Annexin V-FITC/PI flow cytometry analysis. Cell apoptosis analysis was performed using the Annexin V-FITC/PI Apoptosis Detection kit (Becton-Dickinson, San Jose, CA). Cells were seeded into 6 -well plates at a density of $1 \times 10^{6}$ cells/well. After overnight incubation, cells were treated with different concentrations of JB $(0,10,20$ or $40 \mu \mathrm{M})$ for $24 \mathrm{~h}$. LY294002 (50 $\mu \mathrm{M})$ (Sigma, St. Louis, MO, USA), a selective PI3K inhibitor, was added to the culture $1 \mathrm{~h}$ prior to JB $(40 \mu \mathrm{M})$.Then, cold PBS was used to wash the cells twice and the cells were resuspended in $500 \mu \mathrm{l}$ of binding buffer. In the next step, $5 \mu \mathrm{l}$ of Annexin V-FITC and $5 \mu \mathrm{l}$ of PI were added, and the mixture was incubated for $15 \mathrm{~min}$ at room temperature in the dark. After staining, the cell apoptosis was measured immediately by flow cytometry (BD Biosciences, San Jose, CA, USA). Flow cytometry analysis was performed using the FlowJo software (Tree Star, Ashland, OR, USA).

Measurement of mitochondrial membrane potential $\left(\Delta \Psi_{m}\right)$. The loss of $\Delta \Psi \mathrm{m}$ was monitored with the dye Rh123 (Sigma). About $1 \times 10^{6}$ cells were treated with JB $(0,20$ or $40 \mu \mathrm{M})$ for $24 \mathrm{~h}$ or pretreated with LY294002 $(50 \mu \mathrm{M})$ for $1 \mathrm{~h}$ prior to JB $(40 \mu \mathrm{M})$, then harvested and washed in ice-cold PBS followed by incubation with $50 \mu \mathrm{M}$ Rh123 at $37^{\circ} \mathrm{C}$ for $30 \mathrm{~min}$ in the dark. Cells were washed with PBS again and analyzed by flow cytometry at $488 \mathrm{~nm}$ of excitation wave.

Western blot analysis. The cells were treated as described above for the cell apoptosis analysis. The total protein of the cells was extracted with lysis buffer $[20 \mathrm{mM}$ Tris- $\mathrm{HCl}$ at $\mathrm{pH} 7.4$, $0.2 \mathrm{mM}$ EDTA, $1 \mathrm{mM}$ EGTA, $50 \mu \mathrm{g} / \mathrm{ml}$ leupeptin, $250 \mathrm{mM}$ sucrose, $20 \mathrm{mM}$ phenylmethylsulfonyl fluoride (PMSF)]. Cytoplasmic protein was isolated with lysis buffer $(10 \mathrm{mM}$ HEPES pH 7.9, $250 \mathrm{mM}$ sucrose, $10 \mathrm{mM} \mathrm{KCl,} 2 \mathrm{mM} \mathrm{MgCl}$, $0.1 \mathrm{mM}$ EDTA, $1 \mathrm{mM}$ DTT, $10 \% \mathrm{NP}-40)$. Cell lysates were centrifuged at $12,000 \times \mathrm{g}$ for $20 \mathrm{~min}$ at $4^{\circ} \mathrm{C}$ and the protein
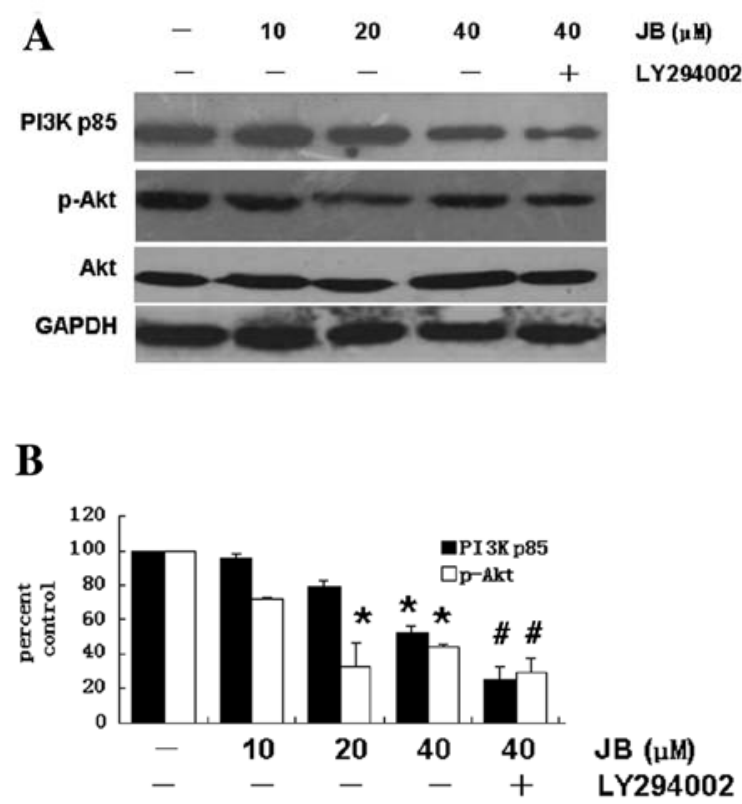

Figure 2. Effect of JB on the expression of PI3K p85 and p-Akt in MDAMB-231 cells. MDA-MB-231 cells were treated with various $(0,10,20$ or $40 \mu \mathrm{M}) \mathrm{JB}$ alone and/or pretreated with $50 \mu \mathrm{M}$ LY294002 for $1 \mathrm{~h}$ followed by co-incubation with JB $(40 \mu \mathrm{M})$ for $24 \mathrm{~h}$. (A) Proteins were extracted, then PI3K p85, Akt and p-Akt expressions were determined by western blot analysis. (B) Densitometric values of protein bands were normalized to those of GAPDH. The intensity of each band was quantified by densitometry, where the control group was assigned the value of $100 \%$. The data represent the mean \pm SD of three independent determinations. ${ }^{*} \mathrm{p}<0.05$ compared with the untreated cells. ${ }^{\#} \mathrm{p}<0.05$ compared to JB alone.

concentration was determined using the Bicinchoninic Acid (BCA) Protein Assay kit (Beyotime Biotechnology, Haimen, China) according to the protocol provided by the manufacturer. Equal amounts of protein $(40 \mu \mathrm{g})$ were separated by SDS-PAGE and electrotransferred onto nitrocellulose filter membranes. The membranes were blocked with a solution of $5 \%$ non-fat dry milk for $2 \mathrm{~h}$ at room temperature, followed by incubation overnight at $4^{\circ} \mathrm{C}$ with primary antibodies against PI3K p85, Akt and p-Akt (Cell Signaling, Danvers, MA, USA), caspase-3, Bcl-2, Bax, cytochrome c (Santa Cruz Biotechnology, Santa Cruz, CA, USA). The membranes were further incubated for $1 \mathrm{~h}$ at room temperature with horseradish peroxidase-conjugated respective secondary antibodies (Cell Signaling). Following washing, the specific proteins were detected using an ECL western blotting kit (Amersham Biosciences, Piscataway, NJ, USA) as recommended by the manufacturer. Each experiment was repeated three times. An internal control was used to confirm that an equal amount of protein was loaded in each lane. Band intensities were quantified by an AlphaImager ${ }^{\mathrm{TM}} 2200$ using the Spot Denso function of the AlphaEaseFC ${ }^{\text {тм }}$ Software version 3.1.2 (Witec, Littau, Switzerland).

Statistical analysis. The data are expressed as mean \pm SD from at least three experiments and were analyzed using the SPSS13.0 statistical software. Differences between two treatment groups were evaluated by the t-test and intergroup differences were evaluated by one-way ANOVA. Statistically significant differences were considered those with $\mathrm{p}<0.05$. 
A
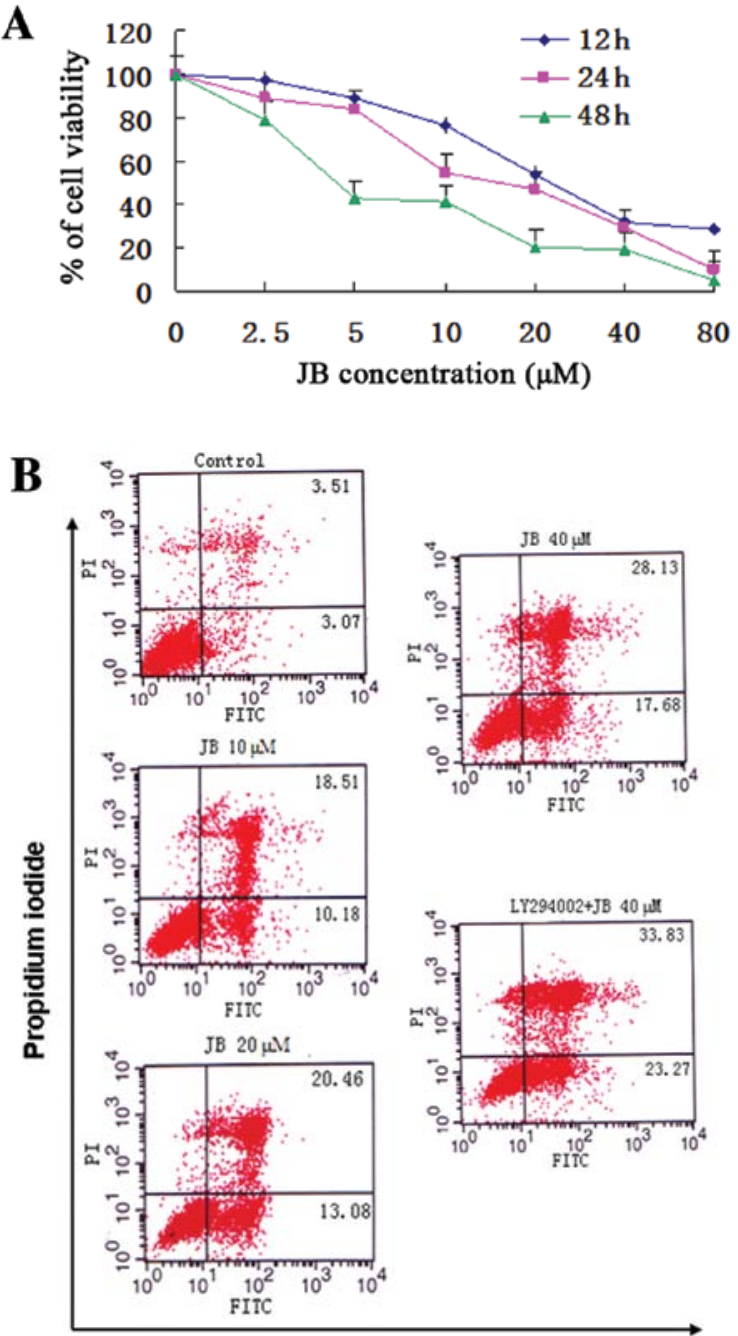

FITC-Annexin V
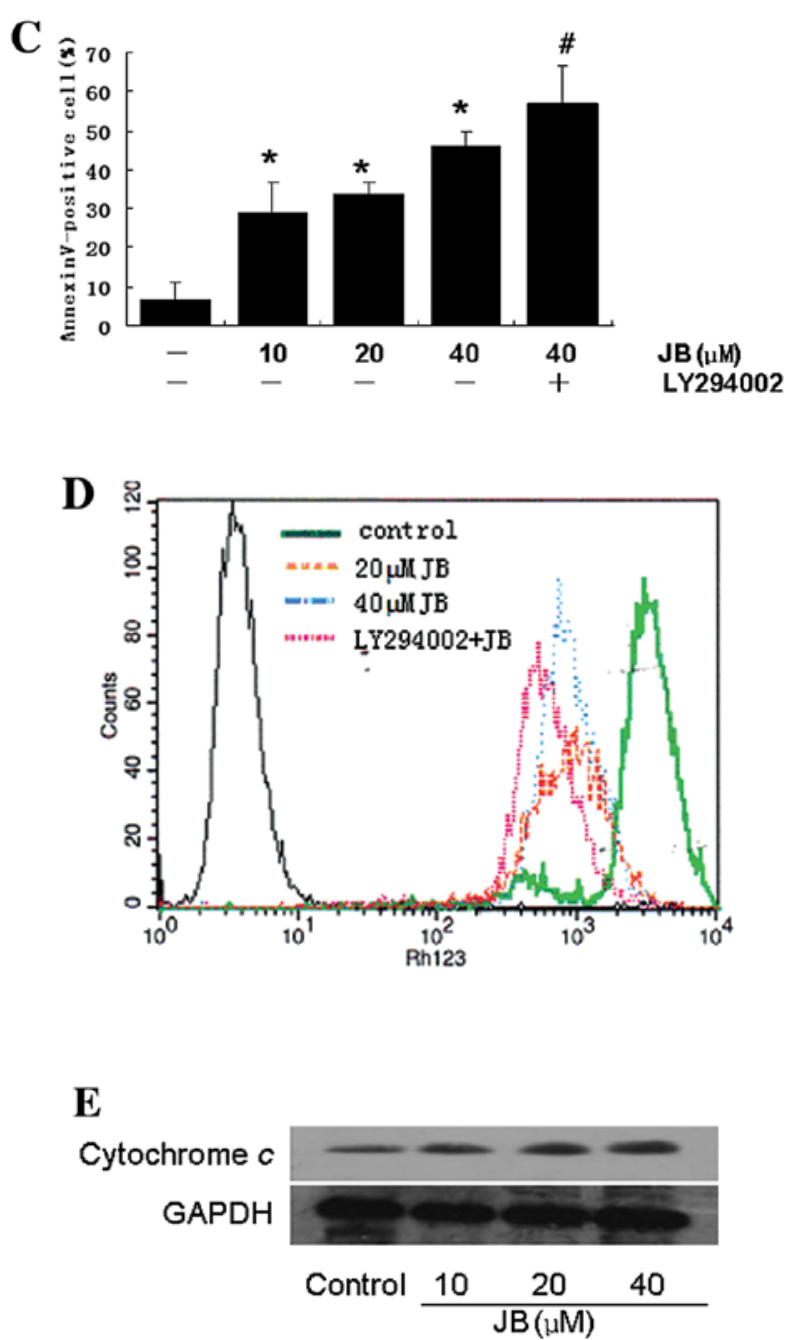

Figure 3. Effect of JB on the proliferation and apoptosis of MDA-MB-231 cells. (A) Proliferation of MDA-MB-231 cells was analyzed by the MTT assay. Cells were treated with various concentrations of JB for 12,24 or $48 \mathrm{~h}$. Cell viability was detected by the MTT assay. Values are expressed as means \pm SD from three independent experiments. (B) Apoptosis induced by JB was assessed with Annexin V-FITC/PI double staining. Cells were treated with JB (0, 10, 20 or $40 \mu \mathrm{M})$ for $24 \mathrm{~h}$ and/or pretreated with LY294002 $(50 \mu \mathrm{M})$ for $1 \mathrm{~h}$ prior to JB $(40 \mu \mathrm{M})$. Cells were then harvested and stained for Annexin V-FITC/PI and analyzed by flow cytometry. The numbers indicate the percentage of cells in each quadrant. (C) The bar chart describes the percent distribution of apoptotic cells. Data were obtained from three separate experiments and are expressed as mean \pm SD. * $p<0.05$ compared with the untreated cells. ${ }^{*} \mathrm{p}<0.05$ compared with JB alone. (D) JB induces the depletion of the mitochondrial membrane potential $(\Delta \Psi \mathrm{m})$. Cells treated with the indicated reagent or combination were harvested and stained with the Rh123 dye and then analyzed by flow cytometry. (E) Western blot analysis for cytochrome c in the cytosolic extract of cells treated with JB $(0,10,20$ or $40 \mu \mathrm{M})$.

\section{Results}

$J B$ suppresses PI3K/Akt phosphorylation. In order to determine the effect of JB on the PI3K/Akt signaling pathway, MDA-MB-231 cells were treated with various concentrations of JB $(0,10,20$ or $40 \mu \mathrm{M})$ for $24 \mathrm{~h}$ and analyzed for the expression of the PI3K/Akt by western blotting. As shown in Fig. 2, protein levels of the PI3K p85 subunit and of phosphorylated Akt were significantly and concentration-dependently suppressed by JB treatment compared with untreated cells.

To further confirm the effect of JB on the PI3K/Akt pathway, cells were pretreated with LY294002 (a specific PI3K inhibitor) prior to JB exposure. The combined treatment with LY294002 $(50 \mu \mathrm{M})$ and JB $(40 \mu \mathrm{M})$ had a synergistic inhibitory effect on PI3K/Akt compared with treatment with JB alone in MDA-MB-231 cells.
$J B$ inhibits growth and induces apoptosis of MDA-MB-231 cells. The PI3K/Akt pathway plays an important role in apoptosis (13). Therefore, we next investigated the effects of $\mathrm{JB}$ on the growth and proliferation of MDA-MB-231 cells, and examined whether JB could induce apoptosis. The MTT assay was performed to examine whether JB inhibits growth of MDA-MB-231 cells. As shown in Fig. 3A, after treatment with various concentrations of JB for 12,24 or $48 \mathrm{~h}$, cell viability and proliferation was markedly inhibited in a doseand time-dependent manner compared with the control group. The calculated $\mathrm{IC}_{50}$ concentrations at 12,24 and $48 \mathrm{~h}$ were $23.82 \pm 4.39,15.29 \pm 2.67$ and $4.68 \pm 1.85 \mu \mathrm{M}$, respectively.

To evaluate whether JB inhibited the survival of MDA-MB231 cells through the induction of apoptosis, cells were treated with different doses of JB $(0,10,20$ or $40 \mu \mathrm{M})$ for $24 \mathrm{~h}$. Then cells were stained with Annexin V-FITC/PI to assess the apop- 

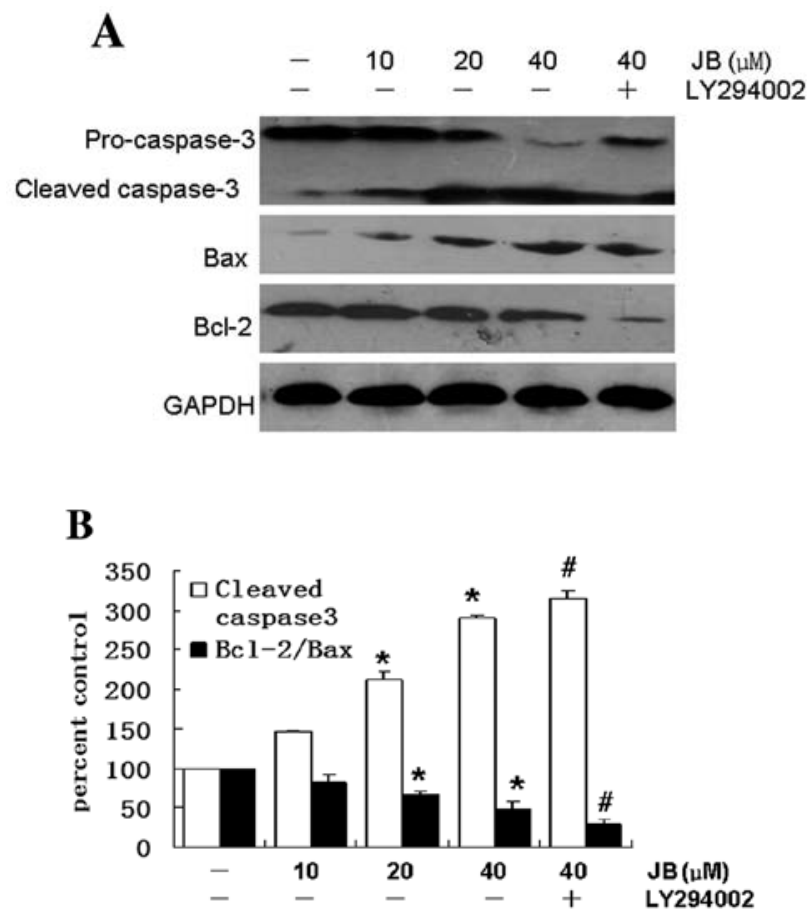

Figure 4. Effect of JB on the expression of caspase-3 and Bcl-2/Bax protein in MDA-MB-231 cells. Cells were treated with increasing doses of JB for $24 \mathrm{~h}$. LY294002 $(50 \mu \mathrm{M})$ was added to the culture $1 \mathrm{~h}$ prior to JB $(40 \mu \mathrm{M})$. (A) Whole cell extracts were prepared for western blot analysis of the indicated proteins. (B) Quantitative results of caspase- 3 and Bcl-2/Bax are presented relative to control. Densitometric analysis of western blot obtained from three independent experiments and are expressed as mean \pm SD. ${ }^{*} p<0.05$ compared with untreated cells. ${ }^{\#} \mathrm{p}<0.05$ compared to JB alone.

totic and necrotic cell population by flow cytometry analysis. Treatment with JB led to marked cell apoptosis indicated by the percentage of Annexin V-positive cells compared with the untreated control (Fig. 3B and C). Pretreatment of MDA-MB231 cells with LY294002 at $50 \mu \mathrm{M}$, prior to JB $(40 \mu \mathrm{M})$ exposure, significantly enhanced the JB-induced cell apoptosis.

Potential changes in mitochondrial membrane potential $\left(\Delta \Psi_{\mathrm{m}}\right)$ were analyzed by flow cytometry with the Rh123 dye. MDA-MB-231 cells treated with JB were found to display a concentration-dependent decrease in $\Delta \Psi_{\mathrm{m}}$ and increase in cytochrome c levels in the cytosol (Fig. 3D and E). LY294002 $(50 \mu \mathrm{M})$ pretreatment encouraged JB-induced loss of $\Delta \Psi \mathrm{m}$.

Effect of JB on protein expression of genes related to apoptosis. Bcl-2 family members are important regulators of the apoptotic pathway $(14,15)$. Therefore, we determined the effect of JB on Bcl-2 and Bax protein levels and the role of the PI3K/Akt signaling pathway. JB treatment significantly decreased Bcl-2 protein levels and increased Bax expression. Meanwhile, the combined treatment with JB and LY294002 $(50 \mu \mathrm{M})$ showed a synergistic effect on $\mathrm{Bcl}-2$ and Bax protein expression (Fig. 4).

We further determined the activation of caspase- 3 by western blot analysis (Fig. 4). Cells treated with JB $(0,10,20$ or $40 \mu \mathrm{M})$ significantly increased the cleavage of pro-caspase-3 to the active form in a dose-dependent manner. In addition, pretreatment with LY294002 $(50 \mu \mathrm{M})$ resulted in an increase in cleaved caspase- 3 .

\section{Discussion}

The dried roots of Euphorbia fischeriana Steud have a long history of being used as folk medicine. Its antitumorigenic constituents, such as the diterpenoid compound 17-acetoxyjokinolide B and Jolkinolide B, have been identified (10). However, its molecular mechanism remains largely unknown. In the present study, JB inhibited the proliferation of MDA-MB-231 cells and markedly induced apoptosis. Meanwhile, JB significantly induced downregulation of the $\mathrm{Bcl}-2 / \mathrm{Bax}$ ratio, thus facilitating cytochrome c release, loss of $\Delta \Psi \mathrm{m}$ and caspase-3 activation. In addition, we found that the Akt-dependent signaling pathway could be involved in the effect of JB in MDA-MB-231 cells.

The execution of apoptosis is an important mechanism of anticancer drugs. It can be initiated via two crucial pathways: the death receptor-mediated and the mitochondrial-mediated pathways. The mitochondrial death pathway is controlled by Bcl-2 family proteins (16). It consists of pro-apoptotic (Bim, Bax and Bid) and anti-apoptotic members (Bcl-2, Bcl-xL) (17-19). During apoptosis, the Bcl-2 family can regulate the release of apoptotic factors and induce or prevent apoptosis. Alteration in the levels of anti- and pro-apoptotic Bcl-2 family members can influence apoptosis. In this study, JB inhibited the proliferation of MDA-MB-231 cells in a dose- and timedependent manner. Furthermore, JB could markedly promote apoptosis of MDA-MB-231 cells, and was associated with downregulation of the $\mathrm{Bcl}-2 / \mathrm{Bax}$ ratio.

Caspase family proteins are critical enzymes to execute apoptosis (20). Although caspase-3 has been documented to play a key role as an executor for apoptosis in mammalian cells $(21,22)$, it is not clear whether caspase-3 is involved in JB-induced apoptosis of MDA-MB-231 cells. As shown in Fig. 4, JB dose-dependently resulted in the activation of caspase-3 in JB-treated MDA-MB-231 cells. The results indicate that caspase-3 may modulate JB-induced apoptosis of MDA-MB-231 cells.

Mitochondria play an important role in regulation of apoptosis. The mitochondrial membrane potential is an important measure for mitochondrial functions. The decrease in $\Delta \Psi \mathrm{m}$ is one of the earliest events in cell apoptosis (23). Disruption of mitochondrial integrity is one of the early events leading to apoptosis (24-26). Therefore, to determine whether JB affects the function of mitochondria, potential changes in the mitochondrial membrane were analyzed by flow cytometry with the dye Rh123. Rh123 is a cell permeable cationic fluorescent probe. It can pass through cell membranes and assemble in living mitochondria. During apoptosis, the $\Delta \Psi_{\mathrm{m}}$ and the fluorescence intensity decrease. In this study, $\Delta \Psi \mathrm{m}$ loss and the release of cytochrome $\mathrm{c}$ were increased in JB-treated cells (Fig. 3D and E). The measurements for $\Delta \Psi \mathrm{m}$ further demonstrated that JB may induce apoptosis of MDA-MB-231 cells, which are common mechanisms proposed for the cytotoxic effects of JB.

The PI3K/Akt signal transduction pathway was reported to play an essential role in various cellular processes including apoptosis, survival, proliferation and differentiation $(27,28)$. Activated PI3K initiates the activation of the downstream kinase Akt. Moreover, phosphorylated Akt could facilitate cell survival and proliferation and regulate various signaling 
pathways (29-31). It has been shown that the activation of PI3K and Akt could inhibit autophagy (32). Yuan et al confirmed that there is a close relationship between the excessive expression and activation of Akt kinase and the malignant biological behavior of ovarian cancer (33). Pretreatment with LY294002 induced apoptosis of ovarian cancer cells (3). The PI3K/Akt signaling pathway has been closely related to the occurrence of human malignant tumors, such as endometrial cancer and non-small cell lung cancer $(34,35)$. In this study, JB treatment of MDA-MB-231 cells decreased the expression of the PI3K p85 subunit, and of the phosphorylated Akt in a concentrationdependent manner (Fig. 2). Additionally, pretreatment with the PI3K pharmacological inhibitor LY294002 $(50 \mu \mathrm{M})$ before JB $(40 \mu \mathrm{M})$ enhanced the effects of JB on the expression of PI3K/ Akt, inducing apoptosis, downregulation of the ratio of Bcl-2/ Bax or activation of caspase- 3 and the release of cytochrome $\mathrm{c}$.

In conclusion, our findings demonstrate that JB induces apoptosis of MDA-MB-231 cells, at least in part, by inhibition of the PI3K/Akt signaling pathway. This seems to be the important mechanism of the JB-induced suppression of the growth of the breast cancer cells. Therefore, JB may serve as a novel promising compound in cancer therapy. Future studies are geared toward evaluating the antitumor activity of JB in animal models.

\section{Acknowledgements}

This research was supported by the National Natural Science Foundation of China (no. 30973902).

\section{References}

1. Harrington KJ, Kazi R, Bhide SA, Newbold K and Nutting CM Novel therapeutic approaches to squamous cell carcinoma of the head and neck using biologically targeted agents. Indian J Cancer 47: 248-259, 2010.

2. Sinha R and EI-Bayoumy K: Apoptosis is a critical cellular event in cancer chemoprevention and chemotherapy by selenium compounds. Curr Cancer Drug Targets 4: 13-28, 2004.

3. Weir NM, Selvendiran K, Kutala VK, et al: Curcumin induces $\mathrm{G} 2 / \mathrm{M}$ arrest and apoptosis in cisplatin-resistant human ovarian cancer cells by modulating Akt and p38 MAPK. Cancer Biol Ther 6: 178-184, 2007.

4. Maddika S, Ande SR, Panigrahi S, et al: Cell survival, cell death and cell cycle pathways are interconnected: implications for cancer therapy. Drug Resist Updat 10: 13-29, 2007.

5. Aziz SA, Davies M, Pick E, et al: Phosphatidylinositol-3-kinase as a therapeutic target in melanoma. Clin Cancer Res 15 3029-3036, 2009.

6. Bader AG, Kang S, Zhao L and Voqt PK: Oncogenic PI3K deregulates transcription and translation. Nat Rev Cancer 5: 921-929, 2005

7. Wickenden JA and Watson CJ: Key signalling nodes in mammary gland development and cancer. Signalling downstream of PI3 kinase in mammary epithelium: a play in 3 Akts. Breast Cancer Res 12: 202, 2010.

8. Priulla M, Calastretti A, Bruno P, Azzariti A, Paradiso A, Canti G and Nicolin A: Preferential chemosensitization of PTEN-mutated prostate cells by silencing the Akt kinase. Prostate 67: 782-789, 2007.

9. Zhang D and Fan D: Multidrug resistance in gastric cancer: recent research advances and ongoing therapeutic challenges. Expert Rev Anticancer Ther 7: 1369-1378, 2007.

10. Wang HB, Chu WJ, Wang Y, Ji P, Wang YB, Yu Q and Qin GW: Diterpenoids from the roots of Euphorbia fischeriana. J Asian Nat Prod Res 12: 1038-1043, 2010.
11. Liu WK, Ho JC, Qin G and Che CT: Jolkinolide B induces neuroendocrine differentiation of human prostate $\mathrm{LNCaP}$ cancer cell line. Biochem Pharmacol 63: 951-957, 2002.

12. Luo $\mathrm{H}$ and Wang A: Induction of apoptosis in K562 cells by jolkinolide B. Can J Physiol Pharmacol 84: 959-965, 2006.

13. Oskouian B and Saba JD: Cancer treatment strategies targeting sphingolipid metabolism. Adv Exp Med Biol 688: 185-205, 2010.

14. Oltersdorf T, Elmore SW, Shoemaker AR, et al: An inhibitor of Bcl-2 family proteins induces regression of solid tumor. Nature 435: 677-681, 2005.

15. Thees S, Hubbard GB, Winckler J, Schultz C and Rami A: Specific alteration of the $\mathrm{Bax} / \mathrm{Bcl}-2$ ratio and cytochrome $\mathrm{c}$ without execution of apoptosis in the hippocampus of aged baboons. Restor Neurol Neurosci 23: 1-9, 2005.

16. Brunelle JK and Letal A: Control of mitochondrial apoptosis by the Bcl-2 family. J Cell Sci 122: 437-441, 2009.

17. Leibowitz B and $\mathrm{Yu}$ J: Mitochondrial signaling in cell death via the Bcl-2 family. Cancer Biol Ther 9: 417-422, 2010.

18. Burlacu A: Regulation of apoptosis by Bcl-2 family proteins. J Cell Mol Med 7: 249-257, 2003.

19. Akcali KC, Sahiner M and Sahiner T: The role of bcl-2 family of genes during kindling. Epilepsia 46: 217-223, 2005.

20. Miura T, Chiba M, Kasai K, et al: Apple procyanidins induce tumor cell apoptosis through mitochondrial pathway activation of caspase-3. Carcinogenesis 29: 585-593, 2008.

21. Wang ZB, Liu YQ and Cui YE: Pathways to caspase activation. Cell Biol Int 29: 489-496, 2005.

22. Denault JB, Eckelman BP, Shin H, Pop C and Salvesen GS: Caspase 3 attenuates XIAP (X-linked inhibitor of apoptosis protein)-mediated inhibition of caspase-9. Biochem J 405: 11-19, 2007.

23. Orrenius S, Zhivotovsky B and Nicotera P: Regulation of cell death: the calcium-apoptosis link. Nat Rev Mol Cell Biol 4: $552-565,2003$

24. Ghobrial IM, Witziq TE and Adjei AA: Targeting apoptosis pathways in cancer therapy. CA Cancer J Clin 55: 178-194, 2005.

25. Baines CP, Kaiser RA, Sheiko T, Craigen WJ and Molkentin JD: Voltage dependent anion channels are dispensable for mitochondrial-dependent cell death. Nat Cell Biol 9: 550-555, 2007.

26. Leung AW and Halestrap AP: Recent progress in elucidating the molecular mechanism of the mitochondrial permeability transition pore. Biochim Biophys Acta 1777: 946-952, 2008.

27. Osaki M, Oshimura M and Ito H: PI3K-Akt pathway: its functions and alterations in human cancer. Apoptosis 9: 667-676, 2004.

28. Franke TF: PI3K/Akt: getting it right matters. Oncogene 27: 6473-6488, 2008.

29. Geering B, Cutillas PR and Vanhaesebroeck B: Regulation of classIA PI3Ks: is there a role for monomeric PI3K subunits. Biochem Soc Trans 35: 199-203, 2007.

30. Sussman M: 'AKT'ing lessons for stem cells: regulation of cardiac myocyte and progenitor cell proliferation. Trends Cardiovasc Med 17: 235-240, 2007.

31. Tsurutani J, Steinberg SM, Ballas M, et al: Prognostic significance of clinical factors and Akt activation in patients with bronchioloalveolar carcinoma. Lung Cancer 55: 115-121, 2007.

32. Wu YT, Tan HL, Huang Q, Ong CN and Shen HM: Activation of the PI3K-Akt-mTOR signaling pathway promotes necrotic cell death via suppression of autophagy. Autophagy 5: 824-834, 2009.

33. Yuan ZQ, Sun M, Feldman RI, et al: Frequent activation of AKT2 and induction of apoptosis by inhibition of phosphoinositide3-OH kinase/Akt pathway in human ovarian cancer. Oncogene 19: 2324-2330, 2000.

34. Achiwa Y, Haseqawa K and Udagawa Y: Regulation of phosphatidylinositol 3-kinase-Akt and the mitogen-activated protein kinase pathways by ursolic acid in human endometrial cancer cells. Biosci Biotechnol Biochem 71: 31-37, 2007.

35. Tang JM, He QY, Guo RX and Chang XJ: Phosphorylated Akt overexpression and loss of PTEN expression in non-small cell lung cancer confers poor prognosis. Lung Cancer 51: 181-191, 2006. 